В. Я. Пуйда

Національний університет "Львівська політехніка", кафедра електронних обчислювальних машин

\title{
СПЕЦПРОЦЕСОР ДЛЯ ВИЗНАЧЕННЯ ХАРАКТЕРНИХ ОЗНАК НА ОСНОВІ АЛГОРИТМУ SURF
}

() Пуйда В. Я., 2017

Запропоновано структуру спецпроцесора реалізації алгоритму визначення характерних ознак відеооб'скта на основі алгоритму SURF для спеціалізованої системи технічного зору.

Ключові слова: система технічного зору, відеозображення, характерні ознаки, ідентифікація.

V. Puyda

Lviv Polytechnic National University, Computer Engineering Department

\section{SPECIAL PROCESSOR FOR FEATURE DETECTION BASED ON THE SURF ALGORITHM}

(C) Puyda V., 2017

We propose a structure of special processor implementing feature detection in a video stream based on the SURF algorithm to be used in computer vision systems.

Key words: computer vision, video stream, SURF features, image identification.

\section{Вступ}

Однією з важливих задач, що виникають під час розроблення систем технічного зору, є задача ідентифікації об'єктів за їх відеозображеннями. Ідентифікація передбачає формування дескрипторів характерних ознак об'єкта. Є багато методів визначення характерних ознак на зображеннях. Вибір методу залежить від особливостей об'єктів, специфіки системи технічного зору, складності сцени, допустимих технічних параметрів та апаратних засобів для реалізації.

\section{Аналіз публікацій}

Розробленням систем технічного зору різного призначення, апаратно-програмних компонентів для таких систем, дослідженням методів і алгоритмів виділення характерних ознак, ідентифікації різних типів відеооб'єктів займаються багато фахівців з аналізу та розпізнавання зображень, наприклад [1-3]. У задачах виявлення об' єктів на зображеннях сцени, ідентифікації об'єктів добре зарекомендував себе метод SURF (Speeded-Up Robust Features) [1], призначений для знаходження та опису характерних точок на зображенні. Метод SURF використовується для пошуку на зображенні характерних ознак об'єкта, інваріантних щодо масштабу і повороту та побудови дескрипторів. У роботах $[2,3]$ розглянуто підходи до ідентифікації візуальних об'єктів, зокрема на основі нейронної мережі [3].

Постановка задачі. Вхідне відеозображення сцени - це кадр розміром 256х256 пікселів: $I(i, j), i \in\{0, \ldots, 255\}, j \in\{0, \ldots, 255\}, \epsilon$ монохромним зображенням з 8-бітовими пікселями. 


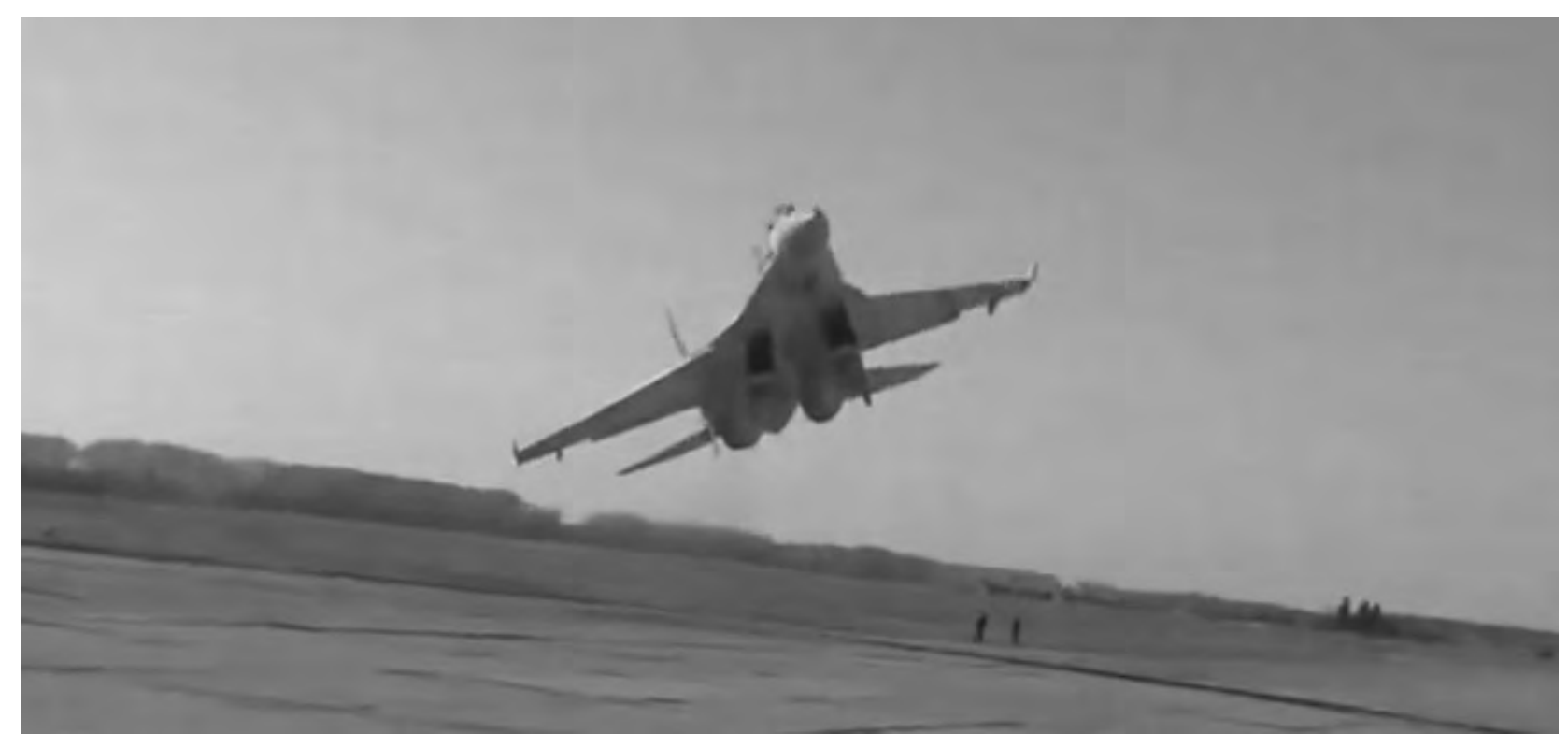

Рис. 1. Відеозображення сичени

На кадрі $I$ кожна точка класифікується в одну з двох груп: точки, які належать об'єкту, і точки, що належать фону:

$$
\{(i, j)\}_{i=0, \ldots, 255, j=0, \ldots .255}=\text { Obj } \cup \text { Backgr }, \text { Obj } \cap \text { Backgr }=\varnothing .
$$

Завдання полягає у відшуканні в кадрі об'єкта, визначенні його характерних точок та побудові дескриптора з метою ідентифікації об'єкта.

Розв'язання задачі. В роботі розглянуто апаратно-програмну реалізацію алгоритму SURF [1] для знаходження та опису характерних точок об’єкта в кадрі відеозображення сцени.

Знаходження характерних точок грунтується на використанні матриці Гесса $H(f)$ зображення $f=f(x, y)$ :

$$
H(f)=\left(\begin{array}{ll}
\frac{\partial^{2} f}{\partial x^{2}} & \frac{\partial^{2} f}{\partial x \partial y} \\
\frac{\partial^{2} f}{\partial x \partial y} & \frac{\partial^{2} f}{\partial y^{2}}
\end{array}\right) .
$$

У дискретному випадку похідні обчислюють за допомогою операції згортки 3 ядрами спеціального вигляду:

$$
H(I, \sigma)=\left(\begin{array}{cc}
L_{x x}(\sigma) & L_{x y}(\sigma) \\
L_{x y}(\sigma) & L_{y y}(\sigma)
\end{array}\right),
$$

де $L_{x x}(\sigma)$ позначає згортку матриці $I$ з похідною $\frac{\partial^{2} g(\sigma)}{\partial x^{2}}, L_{x y}(\sigma)$ - згортку $I$ з похідною $\frac{\partial^{2} g(\sigma)}{\partial x \partial y}, L_{y y}(\sigma)$ - згортку $I$ з похідною $\frac{\partial^{2} g(\sigma)}{\partial y^{2}}$ та $g(\sigma)=g(x, y ; \sigma)$ - ядро Гаусса 3 параметром $\sigma$ :

$$
g(x, y ; \sigma)=\frac{1}{2 \pi \sigma^{2}} e^{-\frac{x^{2}+y^{2}}{2 \sigma^{2}}}
$$


Для пришвидшення обчислень алгоритм SURF використовує апроксимацію похідних $\frac{\partial^{2} g(\sigma)}{\partial x^{2}}, \frac{\partial^{2} g(\sigma)}{\partial x \partial y}$ та $\frac{\partial^{2} g(\sigma)}{\partial y^{2}}$ ядрами прямокутної конструкції:
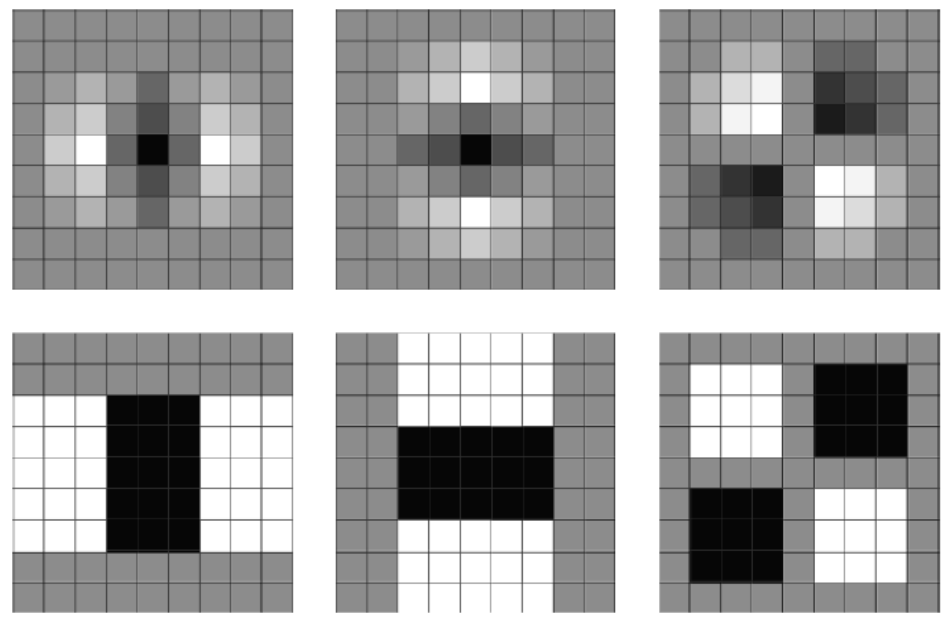

Puc. 2. Апроксимація похідних алгоритмом SURF.

У другому рядку зліва направо ядра $D_{x x}, D_{y y}$ mа $D_{x y}$

На рис. 2 для ядер $D_{x x}$ та $D_{y y}$ білі точки мають вагу - 1, чорні - вагу 2, сірі - вагу 0. Для ядра $D_{x y}$ білі мають вагу -1 , чорні - вагу 1 , сірі - вагу 0.

3 використанням цих ядер визначник матриці Гесса апроксимується за допомогою формули

$$
\operatorname{det} H(I, \sigma)=D_{x x} D_{y y}-\left(0.9 D_{x y}\right)^{2},
$$

де $D_{x x}, D_{y y}$ та $D_{x y}$ позначають згортку зображення $I$ з ядрами відповідного вигляду (рис. 2). За заданого параметра $\sigma$ локальні максимуми функції $\operatorname{det} H(I, \sigma)$ відповідають характерним точкам зображення $I$. Точка $(x, y)$ є характерною точкою зображення $I$, якщо в цій точці досягається локальний максимум функції $\operatorname{det} H(I, \sigma)$ в площині $(x, y)$ та за параметром $\sigma$. Координати характерних точок знаходять із субпіксельною точністю за допомогою розкладу функції $\operatorname{det} H(I, \sigma)$ в ряд Тейлора.

Для пришвидшення обчислення згорток $D_{x x}, D_{y y}$ та $D_{x y}$ алгоритм SURF використовує інтегральні зображення. Для заданого зображення $I$ інтегральне зображення $\tilde{I}$ визначається формулою:

$$
I_{\Sigma}(x, y)=\sum_{i=0}^{x} \sum_{j=0}^{y} I(x, y)
$$

За заданого інтегрального зображення $\tilde{I}$ справедлива формула

$$
\sum_{x=a}^{b} \sum_{y=c}^{d} I(x, y)=I_{\Sigma}(b, d)-I_{\Sigma}(a-1, d)-I_{\Sigma}(b, c-1)+I_{\Sigma}(a-1, c-1)
$$

Приймають $I_{\Sigma}(x, y)=0$, якщо $x<0$ або $y<0$. Задана формула дає змогу отримати суму яскравостей точок зображення у будь-якому прямокутнику за допомогою щонайбільше трьох операцій додавання та віднімання за умови, що інтегральне зображення $I_{\Sigma}$ вже обчислено.

Для досягнення інваріантності щодо повороту кожній характерній точці зображення присвоюєтья орієнтація з використанням ядер Хаара. 

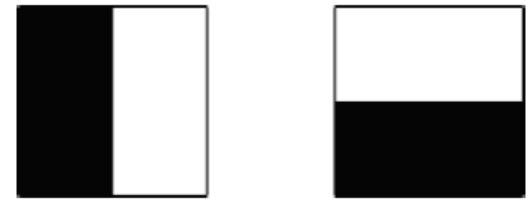

Рис. 3. Ядра Хаара для напрямків $x$ та $y$.

Білі зони мають вагу -1 , чорні вагу 1
Для присвоєння орієнтації характерній точці 3 параметром $\sigma$ знаходять згортки зображення 3 ядрами Хаара розміру $4 \sigma$ у крузі радіуса $6 \sigma \quad 3$ центром у характерній точці. Величини згорток множать на ваговий коефіцієнт, який дорівнює значенню ядра Гаусса 3 параметром $2.5 \sigma \quad 3$ центром у характерній точці. Отримані значення зображують у вигляді точок на площині, абсциса яких дорівнює згортці з ядром Хаара для напрямку $x$ та ордината яких дорівнює згортці з ядром Хаара для напрямку $y$. Кожному сектору радіуса $\pi / 3$ ц центром у початку координат ставлять у відповідність вектор, абсциса якого дорівнює сумі абсцис точок, що містяться у цьому секторі, та ордината якого дорівнює сумі ординат точок, розташованих у цьому секторі. Напрямок найдовшого такого вектора приймають за орієнтацію цієї характерної точки.

Для опису характерної точки навколо цієї точки будують квадратне вікно розміру 20б , поворот якого відповідає орієнтації характерної точки. Це вікно ділиться на 16 квадратних зон, як зображено на рис. 4.

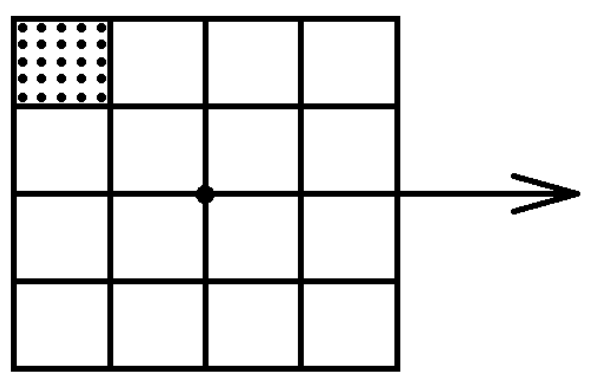

Рис. 4. Побудова дескриптора для характерної точки

У кожній такій зоні вибирають 25 рівномірно розташованих точок, у кожній з яких обчислюється величина згортки 3 ядрами Хаара розміру $2 \sigma$ у напрямках $x$ та $y$. Нехай $x_{i}$ та $y_{i}$ позначають значення згорток для кожної з 25 точок, $i=1, \ldots 25$. Тоді кожній із 16 зон відповідає вектор

$$
\begin{gathered}
v_{j}=\left(\sum_{i=1}^{25} x_{i}, \sum_{i=1}^{25} y_{i}, \sum_{i=1}^{25}\left|x_{i}\right|, \sum_{i=1}^{25}\left|y_{i}\right|\right), \\
j=1, \ldots 16 .
\end{gathered}
$$

Всі 16 векторів $v_{j}$ утворюють 64-вимірний вектор $v$, що $є$ дескриптором характерної точки.

На рис. 6 показано структуру спецпроцесора для реалізації методу SURF на зображенні об'єкта в кадрі 256x256 пікселів. Основою спецпроцесора $є$ швидкодіючий чотириядерний процесор з ядром ARM Cortex-A7.

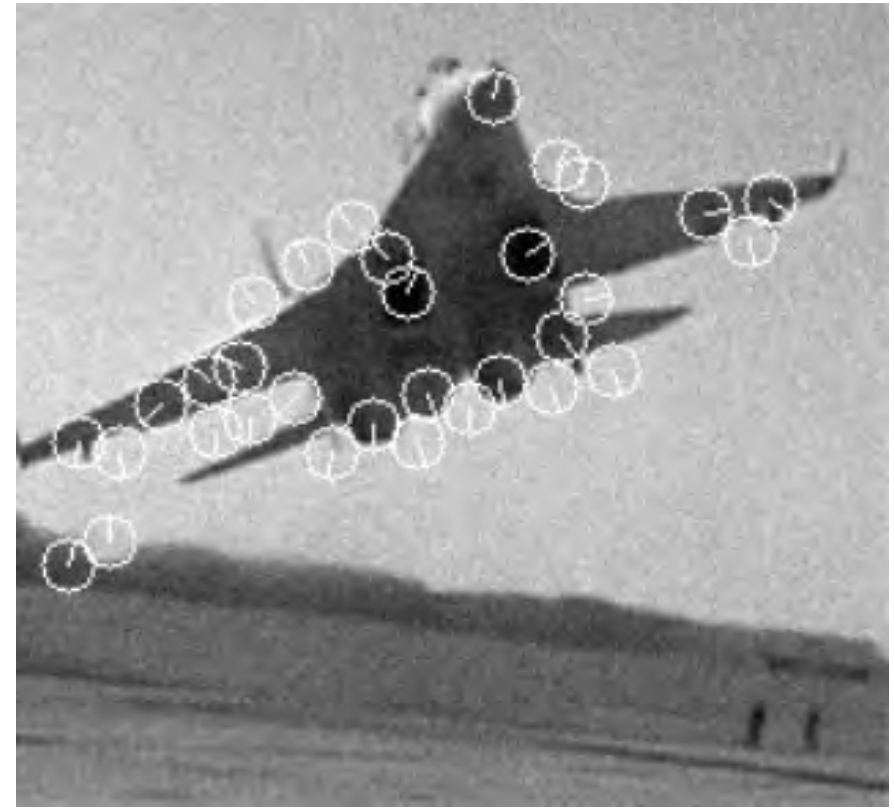

Рис. 5. Визначені характерні точки об єкта в кадрі 256х256 за заданого значення параметра $\sigma$ 


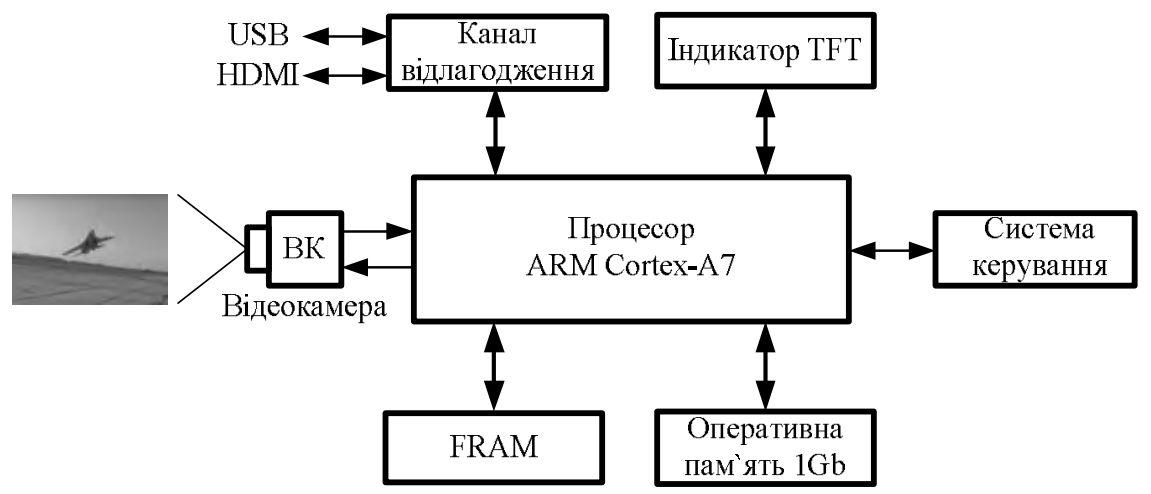

Рис. 6. Структурна схема спецпрочесора для визначення характерних ознак об`єкта

Відлагодження алгоритму визначення характерних ознак об'єкта в кадрі 256x256 пікселів здійснювали на відлагоджувальній платі на базі чотириядерного процесора ARM Cortex-A7 3 робочою частотою $1.6 \mathrm{GHz}$. Зображення сцени з відеокамери надходить через канал спецпроцесора в оперативну пам'ять. Цифрова монохромна спеціалізована відеокамера формує монохромне відеозображення 640x480 восьмирозрядних пікселів. Використання монохромної відеокамери дало змогу мінімізувати об'єм пам'яті відеозображення та підвищити швидкодію під час реалізації методу. Під час введення зображення у пам'ять спецпроцесора зі сцени вирізається відеокадр 3 об'єктом розміром 256x256 пікселів, в якому виконується визначення характерних ознак. Оперативна пам'ять об'ємом 1Gb типу DDR3 використовується для введення з відеокамери зображення сцени та зберігання проміжних даних під час реалізації алгоритму. В пам'яті FRAM зберігаються параметри в процесі функціонування спецпроцесора. FRAM реалізована на базі швидкодіючих мікросхем FM25V10 об'ємом $1 \mathrm{Mb}$, забезпечує швидкодіючі операції читання/запису через послідовний синхронний інтерфейс SPI i може зберігати інформацію, коли вимкнено живлення. Візуальний контроль сцени в полі зору відеокамери забезпечує індикатор на графічному кольоровому дисплеї TFT, на який, крім зображення сцени, виводиться кольорова оперативна інформація для оператора системи. Канал відлагодження містить USB та HDMI інтерфейси. USB 2.0 використовується для підключення системних пристроїв та завантаження у спецпроцесор програм. Через HDMI на дисплей виводиться системна інформація під час відлагодження.

Фрагмент плати спецпроцесора на базі відлагоджувального модуля 3 процесором ARM Cortex-A7 показано на рис. 7, процесор розташований під ребристим радіатором.

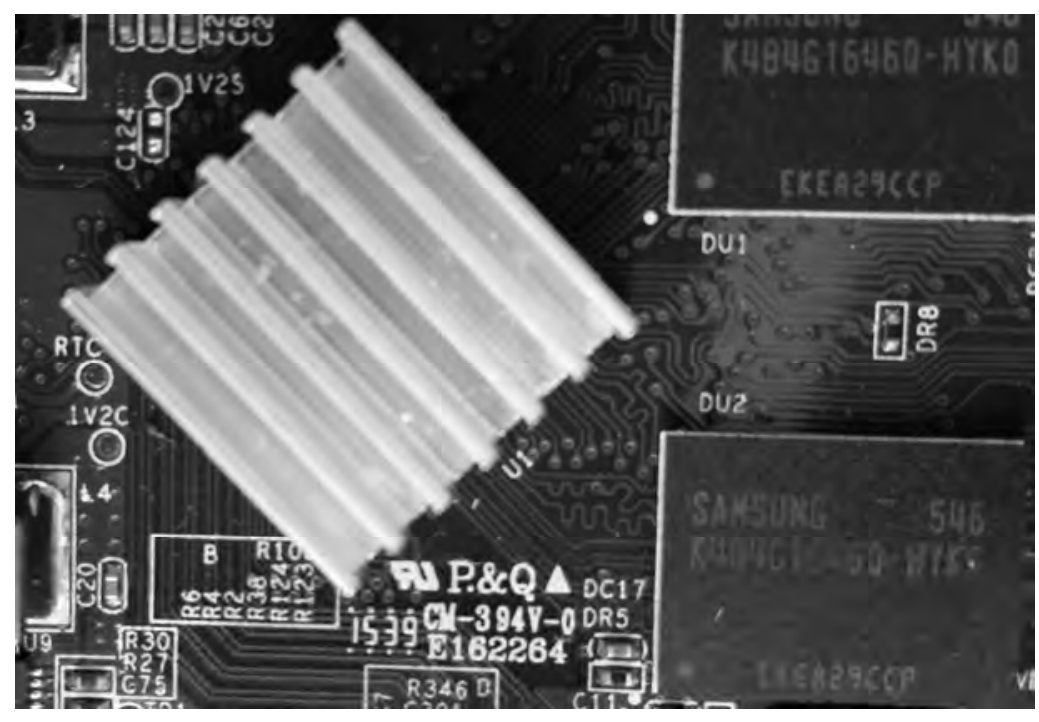

Рис. 7. Фрагмент плати спецฺпрочесора на базі відлагоджувального модуля з прочесором ARM Cortex-A7 
Спецпроцесор для визначення характерних ознак об'єкта на складних сценах можна реалізувати на потужніших засобах, наприклад, TMS320C6678 з восьмиядерною архітектурою ТI Key Stone чи інших подібного класу.

\section{Висновки}

Алгоритм визначення характерних ознак об єкта на монохромному відеозображенні на основі методу SURF можна реалізувати на основі сучасних мікропроцесорних засобів середньої та високої продуктивності для систем технічного зору різного призначення. Ефективність функціонування запропонованої структури спецпроцесора перевірено на базі відлагоджувального модуля 3 процесором ARM Cortex-A7 i робочою частотою 1,6 ГГц. Орієнтовний час формування дескриптора монохромного зображення об'єкта в кадрі 256x256 пікселів не перевищує тривалості одного телевізійного кадру в системі PAL.

1. Baya H., Essa A., Tuytelaarsb T., Van Goola L. Speeded-Up Robust Features (SURF), Computer Vision and Image Understanding 110 (2008), no. 3, 346-359. 2. Pat. 52535 U Ukraine, IPC G 06 K 9/00. Method of automatic identification of visual objects by their silhouettes / Pujda V. Ya., Oleksiv M. V.; Applicant and owner of the patent at the National University "Lviv Polytechnic". - № u201003306; statements. 22.03.2010; has published Aug 25, 2010, Byul. No. 16. 3. Oleksiv M., Pujda V. A System of technical vision for the identification of airplanes based on the neural network // Bulletin of the National University "Lviv Polytechnic" "Computer Science and Information Technologies" No. 638, Lviv, Ukraine, 2009. - P. 61-64. 